NBER WORKING PAPER SERIES

\title{
TESTING FOR PEER EFFECTS USING GENETIC DATA
}

\author{
John Cawley \\ Euna Han \\ Jiyoon (June) Kim \\ Edward C. Norton \\ Working Paper 23719 \\ http://www.nber.org/papers/w23719 \\ NATIONAL BUREAU OF ECONOMIC RESEARCH \\ 1050 Massachusetts Avenue \\ Cambridge, MA 02138 \\ August 2017
}

This research uses data from Add Health, a program project directed by Kathleen Mullan Harris and designed by J. Richard Udry, Peter S. Bearman, and Kathleen Mullan Harris at the University of North Carolina at Chapel Hill, and funded by grant P01-HD31921 from the Eunice Kennedy Shriver National Institute of Child Health and Human Development, with cooperative funding from 23 other federal agencies and foundations. Special acknowledgment is due Ronald R. Rindfuss and Barbara Entwisle for assistance in the original design. No direct support was received from grant P01-HD31921 for this analysis. We thank Olga Yakusheva, Dalton Conley, and participants at the NBER Health Economics meetings for helpful feedback. Cawley thanks the Robert Wood Johnson Foundation for an Investigator Award in Health Policy Research. Corresponding author: John Cawley. The views expressed herein are those of the authors and do not necessarily reflect the views of the National Bureau of Economic Research.

At least one co-author has disclosed a financial relationship of potential relevance for this research. Further information is available online at http://www.nber.org/papers/w23719.ack

NBER working papers are circulated for discussion and comment purposes. They have not been peer-reviewed or been subject to the review by the NBER Board of Directors that accompanies official NBER publications.

(C) 2017 by John Cawley, Euna Han, Jiyoon (June) Kim, and Edward C. Norton. All rights reserved. Short sections of text, not to exceed two paragraphs, may be quoted without explicit permission provided that full credit, including (C) notice, is given to the source. 
Testing for Peer Effects Using Genetic Data

John Cawley, Euna Han, Jiyoon (June) Kim, and Edward C. Norton

NBER Working Paper No. 23719

August 2017

JEL No. D1,I1,I12,I18,J1,Z18

\begin{abstract}
$\underline{\text { ABSTRACT }}$
Estimating peer effects is notoriously difficult because of the reflection problem and the endogeneity of peer group formation. This paper tests for peer effects in obesity in a novel way that addresses these challenges. It addresses the reflection problem by using the alter's genetic risk score for obesity, which is a significant predictor of obesity, is determined prior to birth, and cannot be affected by the behavior of others. It addresses the endogeneity of peer group formation by examining peers who are not self-selected: full siblings. Using data from the National Longitudinal Survey of Adolescent Health, we find evidence of positive peer effects in weight and obesity; having a sibling with a high genetic predisposition raises one's risk of obesity, even controlling for one's own genetic predisposition to obesity. Implications of the findings include that peer effects may be an explanation for continued worldwide increases in weight, and that, because of social multipliers, the cost-effectiveness of obesity treatment and prevention programs may have been underestimated.
\end{abstract}

John Cawley

Department of Policy Analysis and Management

and Department of Economics

Cornell University

2312 MVR Hall

Ithaca, NY 14853

and NBER

JHC38@ cornell.edu

Euna Han

Associate Professor

College of Pharmacy

Yonsei University

162-1 Songdo-Dong

Yeosu-Gu

Incheon, South Korea

eunahan@yonsei.ac.kr
Jiyoon (June) Kim

Department of Economics

Indiana-Purdue University

Fort Wayne

2101 E. Coliseum Blvd

Fort Wayne, IN 46805

june.kim@ipfw.edu

Edward C. Norton

Department of Health Management and Policy

Department of Economics

University of Michigan

School of Public Health

1415 Washington Heights, M3108 SPHII Ann

Arbor, MI 48109-2029

and NBER

ecnorton@umich.edu 


\section{Introduction}

Economists have long been interested in the possibility of peer effects - that an individual's demand may be affected by that of others, through mechanisms other than prices (e.g., Leibenstein, 1950; Manski, 1993; Manski, 2000). This is especially a concern for youth participation in risky health behaviors, such as smoking, alcohol abuse, and drug abuse, as well as for obesity (e.g., Cawley, 2015; Fletcher, 2014; Cawley and Ruhm, 2012). Understanding the role of peer effects, if any, in adolescent risky behaviors is important for designing policies to address these issues.

In this paper we follow the convention of previous studies (e.g., Christakis and Fowler, 2007; Cohen-Cole and Fletcher, 2008a) and refer to the individual whose behavior may be affected as the ego, and the individual who may be affecting them as the alter. Manski (2000) offers three explanations for why risky behaviors are often correlated within peer groups. First, there may be contextual effects, in which the characteristics of the alter (such as age, intelligence, or income) affects the behavior of the ego. Second, there may be correlated effects, in which the ego and alter engage in similar behaviors because they have similar characteristics or environments. Finally, there may be endogenous effects, in which the behavior of the alter directly affects the behavior of the ego. This could operate through several mechanisms, such as shared rivalrous resources (there may be only so many treadmills at the gym or roster spots on the soccer team), expectations (friends may share information about the costs and benefits of various diets or exercises), or individuals directly affecting each other's preferences. An example of the latter is bandwagon effects in which people derive utility from consuming the same goods as their peers (see Leibenstein, 1950). 
Endogenous effects are of particular interest because they imply social multiplier effects; beneficial behavior change by one individual has the potential to spread to others, yielding spillover benefits. In contrast, if only contextual effects and correlated effects exist, there will be no social multiplier or spillover benefits from changing the alter's behavior.

It is notoriously difficult to test for endogenous effects because of the endogeneity of peer groups, the possibility of correlated unobserved variables within peer groups (e.g., rate of time preference, degree of risk aversion, willpower, or family background) and the reflection problem, or the simultaneity of decisions within a group (see, e.g., Angrist, 2014, and Manski, 1993). Yet another issue is that, even if endogenous effects exist, it may be difficult for the researcher to know who are the relevant alters; that is, which peers affect a given behavior (Manski, 2000).

The contribution of this paper is that we estimate peer effects in a novel way that addresses these challenges. We address the simultaneous nature of peer decisions by focusing not on the behavior of the alter but on the alter's genetic risk score; genes are determined prior to birth, and thus cannot be affected by the ego - thus avoiding the reflection problem. The genetic risk score represents a source of exogenous variation in the probability of engaging in the behavior, and thus addresses the issue of unobserved variables that may also affect the behavior. Finally, we address the endogeneity of peer groups by examining peers who did not self-select: full siblings. Siblings are clearly one relevant peer group worthy of examination: siblings spend considerable time together, offering substantial opportunity to influence each other's behaviors (see, e.g., Azmitia and Hesser, 1993). ${ }^{1}$

\footnotetext{
${ }^{1}$ In the data we analyze, siblings have more highly correlated behaviors than nominated friends; see Daw et al., (2015).
} 
We test for peer effects in weight and obesity ${ }^{2}$, which are important outcomes to study. Obesity is highly prevalent in the United States; currently, 37.7\% of U.S. adults aged 20 years and older and $17.0 \%$ of youths aged 2-19 years, are clinically obese (Flegal et al., 2016; Ogden et al., 2016). Excess fat raises the risk of heart disease, Type II diabetes, and cancer (Hu, 2008), and as a result the U.S. spends $\$ 315.8$ billion per year treating obesity-related illness (Cawley et al., 2015) and obesity is one of the top preventable causes of death in the U.S. (Mokdad et al., 2005).

Obesity has been the focus of several previous studies of peer effects. Christakis and Fowler (2007) examine data from the Framingham Heart Study and conclude that obesity spreads within social networks. However, Cohen-Cole and Fletcher (2008a) demonstrate that the empirical approach in Christakis and Fowler (2007), which does not exploit any exogenous variation, cannot distinguish endogenous effects from contextual effects or correlated effects. Cohen-Cole and Fletcher (2008b) subject the model of Christakis and Fowler (2007) to a falsification test, the results of which imply (improbably) that acne, height, and headaches are also spread through social networks. Enriching the model with additional controls for environment and trends greatly diminishes the estimated peer effect, which suggests that the initial finding of peer effects in obesity was spurious and due to omitted variables bias.

Perhaps the strongest evidence of peer effects in weight comes from a study that exploits the natural experiment of randomized roommate assignment among first-year students at two universities (Yakusheva et al., 2014). The randomization of roommates (conditional on a few variables that the researchers observe) solves the problem of endogenous peer groups. The

\footnotetext{
${ }^{2}$ For adults, obesity is defined as a body mass index (BMI) of 30 or higher, where BMI is calculated as weight in kilograms divided by height in meters squared (IOM, 2012). For youths, obesity is defined as exceeding the 95th percentile of the historic weight-for-height distribution (IOM, 2012).
} 
researchers address the reflection problem by examining the influence of the weight of the alter, recorded prior to coming to college, on the ego's weight gain during freshman year. For men, the authors find no significant peer effects, but for women they estimate that a one-standarddeviation increase in the baseline weight of the alter is associated with the ego gaining an additional 0.8 pounds during freshman year, compared to an average freshman year weight gain of 2.4 pounds.

Two studies (Trogdon et al., 2008; Renna et al., 2008) instrument for the weight of an alter using the obesity status of the alter's parents. However, this does not address the problem of peer group endogeneity; youths may be friends because they are both fit or both obese, with the weights of the alter's parents correlated with the alter's weight due to the heritability of weight.

There is suggestive evidence consistent with peer effects in weight from other studies. Carrell et al. (2011) exploited the natural experiment of random assignment of U.S. Air Force Academy cadets to squadrons and found that being assigned to a squadron with less-fit alters was associated with a lower physical education score and a lower probability of passing the Academy's physical fitness requirements. As in Yakusheva et al. (2014), the Carrell et al. (2011) study addresses the endogeneity of peer groups by examining one in which membership is randomly assigned, and addresses the reflection problem by using measures of physical activity from before the cadets arrive at the Academy. Carrell et al. (2011) did not examine weight as an outcome.

Two other studies detect neighborhood effects that could be due in part to peer effects. Kling et al. (2007) and Ludwig et al. (2011), using a randomized experiment, conclude that the Moving to Opportunity program, by incentivizing low-income households to move to higher- 
income neighborhoods, significantly reduced the probability of obesity in the treatment group after five years and reduced the probability of morbid obesity after roughly a dozen years. These neighborhood effects could be due to the change in peers (neighbors) but could also be due to a variety of other factors, such as a more healthful environment (e.g., easier access to fresh vegetables, neighborhoods more conducive to physical activity, and greater safety).

Other recent studies have tested for peer effects in different risky behaviors. One study exploiting the natural experiment of randomized roommate assignment found evidence of positive peer effects in binge drinking but no detectable peer effects in other behaviors such as smoking or drug use (Eisenberg et al., 2014), and a study that exploited the natural experiment of miscarriage found evidence of negative peer effects in teen pregnancy (Yakusheva and Fletcher, 2015). We contribute to this broader literature by exploiting the natural experiment of Mendelian randomization and focusing on the exogenously-determined peer group of full siblings.

\section{Methods}

We test for peer effects in obesity by estimating a reduced-form model in which the ego's weight is regressed on the alter's genetic predisposition to have a high BMI, controlling for the ego's genetic predisposition to have a high BMI, and other control variables. The identifying assumption is that, controlling for the ego's genetic predisposition to a high BMI, the alter's genetic predisposition to high BMI would only affect ego weight through peer effects. Because the sample consists only of full siblings, any correlation cannot be due to self-selection. One strength of the reduced-form approach is that it does not restrict the possible mechanisms for such peer effects. For example, they may operate through changing calorie intake (diet), 
changing calorie expenditure (physical activity), or changing preferences about weight or appearance. Any and all such effects will be reflected in the reduced-form estimate.

In contrast, to estimate a model of instrumental variables in which the alter's BMI is instrumented using the alter's genetic predisposition to a high BMI would be less attractive because it would assume that peer effects only operated through the alter's BMI (Cawley, Han, and Norton, 2011; Scholder et al., 2011; Scholder et al., 2016). However, there may be peer effects that operate through diet and physical activity even after controlling for the alter's BMI. Moreover, one would be concerned in an IV model about pleiotropy — the possibility that genes affect multiple traits (Cawley, Han, and Norton, 2011; Conley and Fletcher, 2017). In an IV model, that would bias the estimates of how the alter's weight affects the ego's weight. However, our focus is not on the mechanism but instead the bigger question of whether peer effects in weight exist at all, through any mechanism. If for any reason the alter's genetic risk score for obesity is correlated with the ego's weight (controlling for the ego's genetic risk score for obesity), that represents evidence of peer effects. In summary, the reduced-form model is most appropriate for this study.

We next explain our reduced-form models in detail. Our basic model regresses the ego's weight $(Y)$ on the alter's genetic risk score (GRS) for obesity (more detail about the GRS is provided in the Data section), the ego's GRS for obesity, and various other ego-level exogenous explanatory variables $X$ :

$$
Y_{i}=\beta_{0}+\beta_{1} \cdot \text { AlterGR }_{i}+\beta_{2} \cdot \text { EgoGRS }_{i}+\beta_{3} \cdot X_{i}+\epsilon_{i}
$$

The dependent variable $Y$ is either continuous BMI or a binary indicator for obesity. When BMI is the dependent variable, we estimate OLS models. When the indicator of obesity is the dependent variable we estimate linear probability models. 
The main variable of interest is the alter's continuous GRS for obesity (AlterGRS). If there are peer effects from the alter to the ego, then we expect the coefficient on AlterGRS to be nonzero. The model also controls for the ego's GRS (EgoGRS), and the vector $X$ includes the following set of control variables: the respondent's age in years; sex (male with female as the reference); race (African-American, Hispanic, other, with White as the reference); an indicator for whether the respondent lives with his/her parents; an indicator for whether the siblings appear to be cohabiting (see the following Data section for details); total household income $(20,000$ 40,$000 ; 40,000-50,000 ; 50,000-75,000 ; 75,000-99,000 ;>100,000$ with less than 20,000 as the reference); the respondent's highest grade completed (high school graduate, less than college, Bachelor's degree or more, with less than high school graduate as the reference); parental educational attainment (high school graduate, less than college, Bachelor's degree or more, with less than high school graduate as the reference); respondent's marital status (married with not married as the reference); and respondent's employment status (work full time, part time, with unemployed or out-of-labor force as the reference). When we test for heterogeneous treatment effects by subgroup, then we also control for the difference in age between the siblings, and whether they are of the same sex. The identically independently distributed error term is $\epsilon_{i}$.

To avoid the selection bias that would result from studying a self-selected peer group, the peer group we study are full siblings (i.e., siblings with the same two parents). This is also attractive because genetic endowment can be considered a natural experiment conditional on having the same parents; each sibling is then getting a draw from the same urns of parental genes. Thus, only full siblings are included in our main sample.

We estimate separate models for twins because they may exhibit different patterns of peer effects than other types of siblings. Specifically, twins may actively seek to establish their 
own identities, or more enthusiastically mimic each other. Models can only be estimated for dizygotic (DZ; i.e., fraternal) twins for two reasons: 1) ego and alter genes are perfectly collinear for MZ twins and thus there is no independent variation in the regressor of interest, AlterGRS, controlling for EgoGRS; and 2) our dataset contains genetic data for only two pairs of monozygotic (MZ; i.e., identical) twins.

One might hypothesize that not all peers are equally influential (Coleman, 1961). For example, Yakusheva et al. (2014) found in their study of college roommates that higher-status alters (defined as those who were higher socioeconomic status or more sexually experienced) were more influential than lower-status alters. In the study of Air Force cadets by Carrell et al. (2011), the least fit alters were most influential; the most fit did not exhibit a beneficial influence. Likewise, in our study, it may be that siblings do not affect each other equally; specifically, older siblings and same-sex siblings may be more influential. It is also possible that the egos may differ in how much they are influenced.

To investigate the possibility of heterogeneous effects, we estimate the regression model for different subsamples: 1) ego is older than the alter; 2) ego is younger than the alter; 3) siblings are the same sex; 4) siblings are of different sex; 5) ego is female; 6) ego is male; 7) ego is non-white; 8) ego is white; 9) ego has a GRS above the mean; and 10) ego has a GRS below the mean. Another possibility is that peer effects in obesity vary by ego weight; to examine this possibility, we estimate quantile regressions as an extension.

As another extension, we also estimate models for half-siblings and unrelated siblings (i.e., stepsiblings). Such siblings are less ideal than full siblings when testing for peer effects because: 1) there may be selection into the peer group that creates a correlation between the ego and alter; e.g., two single parents may be more likely to marry if their children are similar; 2) the 
ego and alter did not draw genes from the same two urns of parental genes, and thus it is a less clean Mendelian randomization.

In all cases, we estimate our models for three waves of data pooled, as well as for each wave separately. It is not possible to estimate an individual fixed effects model because the GRS for both egos and alters are time-invariant.

Each individual in the sample can appear in up to two observations per wave of the data: one in which they are the ego (i.e., their weight is the dependent variable) and one in which they are the alter (i.e., their GRS is the key independent variable). In a small number of households (25-31, depending on the wave) we have complete data for three full siblings and each can serve as the alter for each of the other two; such individuals can appear in up to three observations per wave: one as the ego and two as the alter. To account for the correlation in error terms that results from having egos that reside in the same household, we cluster the standard errors by household.

\section{Data: National Longitudinal Study of Adolescent to Adult Health (Add Health)}

The National Longitudinal Study of Adolescent to Adult Health (Add Health) is a longitudinal study of a nationally representative sample of adolescents. ${ }^{3}$ Wave I of the study started with adolescents in grades 7-12 during the 1994-95 school year. Wave II surveyed the same adolescents in 1996, one year after Wave I. In Wave III, respondents were re-interviewed as they were entering young adulthood, aged 18-26, in 2001-2002. Wave IV followed in 2008-2009. The Add Health collects extensive information ranging from respondents' social, economic, and psychological conditions to their physical well-being.

\footnotetext{
${ }^{3}$ See the Add Health webpage: http://www.cpc.unc.edu/addhealth
} 
The Add Health data are uniquely useful for this analysis because they contain a large number of siblings as well as genetic data. The design of Add Health includes an oversample of about 3,000 pairs of individuals with varying genetic relatedness, including twins, full siblings, half-siblings, and adolescents with no biological relationship but who were raised in the same household (Harris et al., 2013). In Wave IV, trained field interviewers collected saliva samples from respondents who were members of sibling pairs ${ }^{4}$, which were then shipped to a lab for DNA extraction and genotyping (Smolen et al., 2013). ${ }^{5}$ Roughly $96 \%$ consented to data collection and $78 \%$ to archiving of their data.

The genetic risk score for BMI is based on the 32 single-nucleotide polymorphisms (SNPs) that were found to be significantly associated with BMI by Speliotes et al. (2010). The authors report that the mechanisms by which these SNPs affect weight are through regulators of appetite or energy balance, and insulin secretion or response. The genetic risk score is equal to the sum of the alleles in all of the 32 known SNPs that put one at elevated risk of high BMI (Dudbridge, 2013; Domingue et al, 2014). Because each person has at most two such alleles for each of the 32 SNPs, the genetic risk score ranges from 0 to 64 . The Add Health does not release information about the individual SNPs, so we observe the overall genetic risk score but not its individual components.

Although it is estimated that $40-70 \%$ of the variation across individuals in BMI is due to genetic factors, the vast majority of genetic variability in BMI has not yet been linked to

\footnotetext{
${ }^{4}$ Add Health genotyped and calculated BMI risk scores for roughly two-thirds of its sibling pair subsample (McQueen et al., 2015). In Appendix Table 1 we conduct a balance test of the characteristics of Add Health respondents for whom the genetic risk score is available (1,283 individuals) and those for whom it is unavailable (4,388 individuals). Characteristics associated with the risk score being available (as opposed to missing) include race (valid risk score is more likely for African-Americans and less likely for other groups), a more probability that the sibling pairs live with parents, and a lower probability that parents are college graduates.

${ }^{5}$ These Add Health data have been used to study the genetics of BMI and obesity (Domingue et al, 2014; North et al., 2010; Haberstick et al., 2010).
} 
individual SNPs; see, e.g., Locke et al., (2015). Speliotes et al. (2010) estimate that the 32 loci that constitute the genetic risk score collectively explain $1.45 \%$ of the inter-individual variation in BMI. This GRS predicts BMI in the Add Health data as well; specifically, a one-standarddeviation increase in GRS is associated with an increase in BMI of 1.4 BMI units.

A strength of examining the peer effect of the genetic risk score is that one's alleles are determined prior to birth (at conception) and are largely immutable, and thus are not affected by the actions or characteristics of alter. Genes can be altered by retroviruses and replication errors, for example, but these are assumed to be unrelated to ego weight. To clarify, gene expression can be affected by the environment (this is the subject of the field of epigenetics), but generally not one's alleles, and thus one's genetic risk score is exogenously determined.

This genetic risk score for BMI was used by von Hinke Kessler Scholder (2016) as an instrumental variable to estimate the impact of fat mass on academic achievement and blood pressure in English data. Bockerman et al. (2016) use the genetic risk score as an instrument for BMI to estimate the effect of weight on labor market outcomes in Finnish data. This is the first paper to use the genetic risk score for BMI to estimate peer effects.

We identify sibling status among Add Health respondents using the sibling pair variable from Wave I. We drop the sibling pairs if either of them has missing or invalid BMI genetic risk scores. In the final sample, we have 1,283 individuals, and 687 sibling pairs. ${ }^{6}$

Our main dependent variables are a linear measure of BMI and an indicator variable for obesity. We construct BMI using measurements of weight and height, which avoids the complications associated with the reporting error that is common in weight (Cawley, Maclean et al., 2015). Our sample consists of Waves II, III, and IV; new measurements of weight and height

\footnotetext{
${ }^{6}$ In wave 2, we have data for 547 sibling dyads and 25 sibling triads. In wave 3, our sample includes 476 dyads and 24 triads, and in wave 4 it includes 595 dyads and 31 triads.
} 
were taken in each of those waves. We do not examine outcomes for Wave I because no measurements of weight and height were taken; only self-reported data were recorded. As an extension, we estimate models using the self-reported data in Wave I. Respondents aged 20 years and older are classified as obese if their BMI equals or exceeds 30. Those aged 19 and younger are classified as obese using weight-for-height cutoffs that vary by sex and month of age (IOM, 2012).

We control as well as possible, given the limitations of the data, for whether the siblings are cohabiting in the same household at the time of the interview. This information is not explicitly contained in the Add Health, so we impute it in the following manner. In Waves I, II, and IV, we assume that the ego and alter cohabit if the household roster indicates that the respondent is living with a sibling of a gender that matches the alter. In Wave III, we use the variable that asks about travel time to their sibling; we code the ego and alter as cohabiting if the respondent states that they live with their sibling. However, we cannot be sure that the respondent's sibling in this question is the sibling who is the alter in our model.

We estimate models with all waves pooled as well as separately by wave to examine whether peer effects may vary by the age of the respondents, who are age 12-17 in Wave II, age 18-26 in Wave III, and age 25-31 in Wave IV. Peer effects of siblings may be stronger at younger ages, when egos may be more easily influenced.

Observations with missing data for BMI or genetic risk score are dropped from the sample. When data on other control variables are missing, the value is set to zero and an indicator for missing values of that variable is set to one and included in the model.

\section{Results}




\section{Summary Statistics}

Table 1 reports the mean values for variables in the regression model for the sample of full siblings, for the three waves (II, III, and IV) pooled. The mean BMI is 26.76 , and $26.1 \%$ of respondents are obese. The mean genetic risk score is 27.3 and it ranges from 18 to 39 . The mean age at time of interview is 22.6 years. The sample is $47.9 \%$ male, $16.5 \%$ AfricanAmerican, $12.2 \%$ Hispanic, and $10.3 \%$ other race.

\section{Regression Results}

We next present results from model (1), the regression of ego BMI on the genetic risk score of the alter, controlling for the genetic risk score of the ego, and other variables. These results, shown in Table 2, support the hypothesis of peer effects. The first set of columns are for the outcome of obesity, and the second set are for the outcome of BMI. Results are presented for the three waves (II, III, and IV) pooled (in Panel A) as well as for each wave separately (in Panels B, C, and D). The results for the pooled sample (Table 2, Panel A, column 4) indicate that a one-unit increase in the genetic risk score of the alter is associated with a 0.16 unit $(0.6 \%)$ increase in BMI of the ego, which is statistically significant at the 5\% level. The alter's BMI risk score is also associated with a higher probability of the ego being obese; specifically, a one-unit increase in the alter's genetic risk score is associated with a 0.97 percentage point $(3.71 \%)$ increase in the probability of ego obesity, which is statistically significant at the $5 \%$ level. The magnitude of the correlation between the ego's weight and the alter's genetic risk score is large; for obesity it is roughly two-thirds the size of that for the ego's own genetic risk score, and for BMI it is roughly half that of the ego's own genetic risk score. Because of the correlation between the genetic risk scores of the ego and alter (the correlation is 0.57 ), adding the alter's genetic risk score to the model decreases the correlation between ego weight and the ego's own 
genetic risk score (compare the coefficient on the ego's genetic risk score in column 1 which excludes alter genetic risk score, and column 2 which includes it).

These results are generally robust across individual waves, although they are less likely to be statistically significant because of the smaller samples. For example, a one-unit increase in the alter's genetic risk score is associated with an ego's BMI that is higher by 0.11 units $(0.45 \%)$ in Wave II, 0.21 units $(0.8 \%)$ in Wave III, and 0.17 units $(0.59 \%)$ in Wave IV; each is statistically significant at the $10 \%$ level or better (see Panels B through D of Table 1). Likewise, a one-unit increase in the alter's genetic risk score is associated with a probability of ego obesity that is higher by 1.47 percentage points (6.39\%) in Wave III and 1.25 percentage points (3.19\%) in Wave IV; in wave II the association is smaller ( 0.32 percentage points) and not statistically significant at the $10 \%$ level.

We also test for equality of estimated effects across wave and reject the hypothesis that they are equal. We cannot distinguish whether peer effects may be varying with age or with unobserved factors that vary with time.

\section{Testing for Heterogeneous Effects}

We next test for heterogeneous effects, specifically: whether peer effects differ by the relative age of the alter, whether the alter is of the same sex, and by sex and race of the ego. In each of these cases, we estimate the models using the sample of all three waves pooled. Table 3 , Panel A, reports the results of models estimated using pairs in which the ego is older than the alter (columns 1 and 2) and when the ego is younger than the alter (columns 3 and 4). The results indicate that the alter's genetic risk score is significantly correlated with ego weight only when the ego is younger than the alter; the point estimates suggest that the older siblings are more than twice as influential as younger siblings. For example, a one-unit increase in alter 
genetic risk score is associated with an increase in the probability that the ego is obese of 1.5 percentage points (which is statistically significant at the $5 \%$ level) when the alter is an older sibling but of 0.6 percentage points (not statistically significant) when the alter is a younger sibling. However, the difference in the two point estimates is not statistically significant (the $p$ value is presented at the bottom of the panel).

Table 3, Panel B, reports the results of models estimated separately for pairs in which the ego and alter are of the same sex (columns 1 and 2) or are of opposite sex (columns 3 and 4). There is little difference in the point estimates of peer effects on obesity when the ego and alter are of the same sex versus different sex, and that small difference is not statistically significant.

Table 3, Panel C reports results of models estimated separately for pairs in which the ego is female (columns 1 and 2) or the ego is male (columns 3 and 4). The point estimates suggest that female egos are more influenced by their siblings; a one-unit increase in the genetic risk score of the alter is associated with an increase in the probability that the ego is obese of 1.06 percentage points (statistically significant at the $10 \%$ level) for female egos but 0.86 percentage points (not statistically significant) for male egos; this difference is not statistically significant.

Table 3, Panel D reports results of models estimated separately for non-white siblings (columns 1 and 2) and white siblings (columns 3 and 4). The pattern of point estimates suggests that sibling peer effects are greater for non-whites than whites. For example, a one-unit increase in the genetic risk score of the alter is associated with an increase in the probability that the ego is obese of 1.70 percentage points (statistically significant at the $5 \%$ level) for non-whites but 0.68 percentage points (not statistically significant) for whites. Similarly, a one-unit increase in the genetic risk score of the alter is associated with an increase in BMI of the non-white ego by 
0.32 units (statistically significant at the $1 \%$ level), but only by 0.09 units for the white ego. This difference is statistically significant for BMI but not obesity.

\section{Extensions}

\section{Which Egos are Most Influenced, and Which Alters are More Influential?}

In a series of extensions, we examine further whether some egos may be more influenced than others, and whether some alters may be more influential than others. To examine whether a high (low) genetic risk score makes an ego more (less) influenced by their alter, we estimated models separately for egos whose risk score is above (below) average; the results appear in Table 3, Panel E. The results indicate that alter risk score is associated with ego weight only for egos whose risk score is below average; in other words, those less predisposed to obesity are more influenced by their peer. Specifically, a one-unit increase in the alter's genetic risk score is associated with a 1.33 percentage point increase (which is significant at the $5 \%$ level) in the probability of obesity among egos with a below-average genetic risk score, but a 0.6 percentage point increase (which is not statistically significant) among egos with an above-average risk score. However, the confidence intervals around these estimates are relatively wide, so the difference in point estimates between egos who have below-average and above-average GRS is not statistically significant.

We also test whether certain alters are more influential than others. We add to the regression model interactions of the alter's risk score with two indicator variables: for whether the alter's risk score is in the top $20 \%$ or in the bottom $20 \%$ of the alter sample. The model continues to include the main effect of alter risk score. The results generally yield no evidence 
of heterogeneity in alter influence (see Table 4, columns 1 and 2). The interactions in question are not statistically significant for either BMI or obesity.

\section{Results for DZ Twins}

Twins were excluded from our sample of full siblings because they may exhibit different peer effects than other types of siblings. As an extension, we estimated the peer effects model for the sample of DZ twins. The results of the peer effects models for DZ twins are provided in Table 5. Consistently, we find no detectable peer effects, neither in the pooled sample nor in any of the individual waves. Moreover, the point estimates for DZ twins are generally smaller than those for full siblings, and negative. One interpretation is that DZ twins seek to distinguish themselves from each other and are less imitative of each other than other full siblings.

\section{Results for Half-Siblings and Unrelated Siblings}

As an extension, we estimate our basic model for the sample of half- and unrelated siblings. Unlike our sample of full siblings, this sample has the potential to result in biased estimates because the peer groups are endogenous; single parents may be more likely to marry if their children are similar.

Appendix Table 2 reports the summary statistics of regression variables for half-siblings and unrelated siblings. Comparing these means to those for full siblings in Table 1 reveals that the half-siblings and unrelated siblings tend to be of lower socioeconomic status than the full siblings. The half-siblings and unrelated siblings are less likely than the full siblings to have parents who graduated college $(7.3 \%$ versus $18.5 \%)$, graduated college themselves $(2.9 \%$ versus $14.2 \%$ ), or earn an income over $\$ 75,000$ per year (4.0\% versus $18.5 \%)$. The half-siblings and unrelated siblings are also far more likely to be African-American than the full siblings (91.9\% 
versus $16.5 \%$ ). Thus, there are many things that differ between these two samples other than whether the sibling pairs have the same two parents.

The results for half-siblings and unrelated siblings, in Table 6, are quite different from those for full siblings that appear in Table 2 . The alter's genetic risk score is negatively and significantly correlated with ego BMI and risk of obesity in the pooled sample (Panel A of Table 6). When the model is estimated wave-by-wave (see Panels B, C, and D of Table 6), alter genetic risk score is negatively correlated with ego BMI and ego obesity in each wave, although in waves III and IV the correlation with ego obesity is not statistically significant. This discrepancy in results between full siblings and half/unrelated siblings is consistent with the potential for endogenous peer groups to bias estimates of peer effects, but we are wary of drawing too strong a conclusion given the large differences between the samples in race and socioeconomic status.

\section{Results Including, and For, Wave I}

We exclude from our main analysis Wave I of the Add Health because in that wave weight and height were self-reported, rather than measured, and self-reported weight and height contain reporting error that can bias regression coefficients (e.g., Cawley, Maclean, Hammer et al., 2015). However, as a robustness check we include Wave I in our pooled sample; the indicator variables for wave will control in part for differences between waves in data collection. We also report results from models estimated using only Wave I. These results appear in Appendix Table 3.

The results for all four waves pooled, which appear in Panel A of Appendix Table 3, are very similar to the main results (based on Waves II through IV) that appear in Panel A of Table

2. For example, the main results implied that an additional risky allele for the alter raises the 
ego's risk of obesity by 0.97 percentage point, in the new results (based on all four waves) the corresponding estimate is 1.01 percentage points. The estimates for BMI are also very similar.

The estimates based on Wave I alone (which appear in Panel B of Appendix Table 3) imply that an additional risky allele for the alter raises the ego's risk of obesity by 1.06 percentage points. This point estimate is greater than that for Wave II alone ( 0.32 percentage points, which is not statistically significant; see Panel B of Table 2) and somewhat less than those for Waves III and Wave IV alone (1.47 percentage points and 1.25 percentage points, respectively; see Panels C and D of Table 2). In general, results from models that include Wave I in the pooled sample, or are based on Wave I alone, are very consistent with our earlier models that rely solely on Waves II through IV.

\section{Quantile Regression}

The OLS models presented earlier summarize the average relationship between alter GRS around the conditional mean of BMI. However, one might also be interested in knowing the relationship at other points along the conditional distribution of BMI; for example, it is possible that peer effects may be greater for those who are heavier. To investigate this, we estimated quantile regressions, focusing on the relationship at the $50^{\text {th }}, 75^{\text {th }}, 80^{\text {th }}, 85^{\text {th }}$, and $90^{\text {th }}$ percentiles of the BMI distribution. Although the coefficients on alter GRS are not significantly different across percentiles, the pattern of the point estimates suggests that those at the median BMI are less influenced by alters than those at higher percentiles of BMI. For example, the estimated peer effects are larger and statistically significant near the cutoff for obesity $(\mathrm{BMI}=30)$ but not near the cutoff for overweight $(\mathrm{BMI}=25)$. These results are available upon request.

\section{Mechanisms}


Peer effects could operate through a variety of mechanisms, such as diet, participation in sedentary activities (such as watching TV) or physical activity (such as playing sports). The Add Health data contains little information about diet but does include limited information on certain sedentary activities and physical activities. To investigate mechanisms for the positive peer effects found earlier, we estimated models of engaging in the following activities as a function of the GRS of the alter, controlling for the GRS of the ego: playing games (hours per week), watching television (hours per week), whether use a fitness center (binary), whether play sports (binary), whether walk or jog for exercise (binary), whether bike or skate (binary). If these are the mechanisms for the earlier positive peer effects, we would expect that a higher alter GRS would be associated with the ego spending more time playing games and watching television, and a lower probability of the ego engaging in these physical activities.

The results (available upon request) indicate that, in general, the GRS of the alter is not significantly correlated with these activities. The exception is that alter GRS is significantly and positively correlated with the probability that the ego walks or jogs for exercise and the probability that the ego bikes or skates. However, the point estimates are of the opposite sign than expected. It is possible that the walking/jogging and biking/skating build muscle mass which contributes to higher ego BMI (which simply reflects weight for height and does not distinguish muscle from fat), but it is unclear why those activities would be more likely if one has a sibling predisposed to a high BMI. In general, we find little information about mechanisms in the limited data available in the Add Health.

\section{Discussion}

Using genetic data as an exogenous source of variation in peer characteristics, we test for peer effects in obesity among full siblings. We find evidence of positive peer effects on weight 
and obesity; a one-unit increase in the BMI risk score of the alter (which means that the alter has one additional allele that is associated with higher weight) is associated with a 0.16 unit $(0.6 \%)$ increase in BMI of the ego and a roughly one percentage point $(3.71 \%)$ increase in the probability that the ego is obese, both of which are statistically significant at the $5 \%$ level.

This paper contributes to the economic literature on peer effects through its novel use of genetic data to test for peer effects. Yakusheva et al. (2014) examined the impact of randomized assignment to the peer group (college roommates). In contrast, we examine a fixed, exogenously determined peer group (full siblings) and utilize exogenous variation in peer characteristics (genetic endowment). Our study is consistent with Yakusheva et al. (2014) in that both find evidence of positive peer effects in weight, although the models are different; their study found larger changes in ego weight whereas we find a higher level of ego weight.

Previous research has found evidence of heterogeneity in peer effects. Yakusheva et al. (2014) found that only women (not men) were affected by peer weight; they also found that higher-status peers are more influential on their roommates. Carrell (2010) found that the most influential alters were those who were least fit.

We find mixed evidence on the heterogeneity of peer effects. We cannot reject the equality of peer effects when the ego is older, and when the ego is younger, than the alter; when the ego is of the same sex, or different sex, than the alter; when the ego is female versus male; or when the ego's own BMI risk score is above the mean or below the mean. In other cases we find some evidence of heterogeneity in effects; for example, we find that non-whites experience greater peer effects than whites in BMI.

We focus on full siblings, because a full sibling is an exogenously determined peer and thus estimates are unbiased by selection. In contrast, models estimated using half-siblings or 
stepsiblings might be biased by parental selection — the parents might be more likely to marry if their existing children are more similar. In addition, only for full siblings is the natural experiment of Mendelian randomization clean, because only full siblings drew their genes from the same two urns of parental genes (Scholder et al., 2011). In a sensitivity analysis, we find very different results for half-siblings and step-siblings compared to our main sample of full siblings; whereas full siblings exhibit positive peer effects we find negative correlations among step-siblings and half siblings. This illustrates the importance of avoiding selection bias in peer groups.

The results are not due to shared family environment. First, there is relatively little evidence of shared family environment on weight, and what evidence there is tends to disappear by adolescence (see, e.g. Silventoinen et al., 2010), and our sample averages age 22. Second, to the extent that there is any shared family environment effect in adulthood, there is no clear reason why it should exhibit a pattern consistent with our results, having greater influence on individuals whose siblings have relatively more alleles for high BMI than for individuals whose siblings have relatively fewer alleles for high BMI.

The limitations of this study are as follows. The genetic risk score represents the bestavailable knowledge of the SNPs linked to obesity at this time. A large percentage of what is classified as genetic variation in obesity has not yet been associated with any specific SNP (Locke et al., 2015); as genetic knowledge advances, genetic risk scores will be updated to reflect the new knowledge and will undoubtedly become more complete and powerful predictors of weight. To some extent, the risk score may also contain false positives, although all of the included SNPs were robustly associated with weight across multiple datasets and studies (Speliotes et al., 2010). To some extent, the SNPs included in the risk score may exhibit 
pleiotropy; i.e., they may affect characteristics other than weight and obesity. Researchers have investigated this and generally found that these SNPs are only associated with BMI and weightrelated conditions. ${ }^{7}$ However, even if there is pleiotropy, an association of ego weight with alter genetics in an exogenously-determined peer group still provides evidence of peer effects, no matter what trait or behavior is the mechanism.

One might interpret the correlation of alter genes with ego weight as the influence not of the alter but of the two parents who contributed genes to both the ego and the alter. However, this too represents a form of peer effect, just from a different peer group (parents rather than siblings). It is also possible that, if ego genetic risk score is mis-measured, then the correlation we observe may be due to omitted variable bias - alter genetic risk score may be correlated with the unobserved true genetic risk of the ego. However, the peer effect in BMI is roughly half the size of the effect of the ego's own genes, which seems implausibly large to be due solely to mismeasurement in the genetic risk score (for more details on quality and accuracy of the Add Health genome-wide association study, see McQueen et al. 2015 and its online supplement). Moreover, there is no clear reason why any mismeasurement should be correlated with a sibling's number of alleles for high BMI.

Caution should be exercised when generalizing from this study. We examine a specific peer group — full siblings — and the results may not generalize to other peer groups such as

\footnotetext{
${ }^{7}$ Locke et al. (2015) and Speliotes et al. (2010) search the genetics literature for evidence of any pleiotropy of the BMI-related SNPs. Of the 32 SNPs linked to BMI, four are also associated with either Type 2 diabetes, fasting glucose, fasting insulin, or insulin resistance, but this is not surprising because excess fat (by secreting the hormone resistin) causes insulin resistance and thus diabetes ( $\mathrm{Hu}, 2008)$; thus, these can be considered part of the total effect of obesity. Three of the 32 SNPs are also associated with height (Speliotes et al., 2010), but this is a component of BMI and peer effects in height are largely implausible. Two of the 32 SNPs are associated with age of onset of menstruation (menarche), which is also related to fatness (Kaplowitz, 2008; Wang, 2002). Two of the 32 SNPs are linked to cholesterol levels and one to blood pressure; both of these conditions are strongly associated with obesity (e.g., $\mathrm{Hu}, 2008$ ) and thus can be considered part of the effect of obesity. In summary, the few other phenotypes that the obesity-related SNPs are associated with tend to be obesity-related comorbidities.
} 
friends, roommates, or coworkers. Moreover, the results may not generalize to all variation in weight. We measure a specific Local Average Treatment Effect — variation in genetic predisposition to high BMI. It is possible that this has greater peer influence than other sources of variation in alter weight. Finally, the fact that we find evidence of peer effects for BMI and obesity does not necessarily imply that there are also peer effects for behaviors such as smoking, alcohol abuse, or drug use. Future research should seek identification strategies for identifying peer effects for other peer groups, other sources of variation in weight, and other outcomes.

The finding of positive peer effects in obesity has potentially important implications for policy. For example, it represents one possible explanation for rising weights and prevalence of obesity. Worldwide, between 1975 and 2014, mean BMI rose from 21.7 to 24.2 for men and from 22.1 to 24.4 for women (NCD Risk Factor Collaboration, 2016). The prevalence of obesity has also risen dramatically worldwide; all cohorts seem to be gaining weight at all ages (Ng et al., 2014). A wide range of possible contributors has been investigated, including cheaper food, higher incomes, as well as viruses and changes in gut microbes (see, e.g., Ng, 2014; Cawley, 2015), but peer effects represent another possible contributor that would be particularly troubling as it entails the possibility that increases in weight may become self-perpetuating, as peers influence each other in feedback loops. Social multiplier effects also represent a possible externality (Sassi, 2010) which may in turn represent an economic rationale for government intervention to prevent and reduce obesity (Cawley, 2015).

Methods of obesity prevention and treatment could also exhibit social multiplier effects (Sassi, 2010). Programs that prevent weight gain or facilitate weight loss may benefit not just the individuals who participate in the program, but also their peers. If true, it implies that the cost-effectiveness of obesity prevention and treatment programs has been underestimated. 


\section{Works Cited}

Azmitia, M., J. Hesser. 1993. Why Siblings Are Important Agents of Cognitive Development: A Comparison of Siblings and Peers. Child Development, 64(2): 430-444.

Angrist, J.D. 2014. The perils of peer effects. Labour Economics. 30:98-108.

Bockerman, P., J. Cawley, J. Viinikainen, T. Lehtimaki, S. Rovio, I. Seppala, J. Pehkonen, O. Raitakari. 2016. The Effect of Weight on Labor Market Outcomes: An Application of Genetic Instrumental Variables. NBER Working Paper \#22200.

Carrell, S.E., M. Hoekstra, J.E. West. 2011. Is poor fitness contagious? Evidence from randomly assigned friends. Journal of Public Economics 95(7-8):657-663.

Cawley J. 2015. An Economy of Scales: A Selective Review of Obesity's Economic Causes, Consequences, and Solutions. Journal of Health Economics, 43: 244-268.

Cawley, J., C. Meyerhoerfer, A. Biener, et al. 2015. Savings in medical expenditures associated with reductions in body mass index among US adults with obesity, by diabetes status. Pharmacoeconomics 33(7):707-722.

Cawley, J., E. Han, and E.C. Norton. 2011. The Validity of Genes Related to Neurotransmitters as Instrumental Variables. Health Economics 20(8):884-888.

Cawley, J., J.C. Maclean, M. Hammer et al. 2015. Reporting error in weight and its implications for bias in economic models. Economics and Human Biology 19:27-44.

Cawley, J. and C.J. Ruhm. 2012. The economics of risky health behaviors. Handbook of Health Economics, Volume 2, eds. Pauly, M.V., T.G. McGuire, and P.P. Barros, pp. 99-195.

Christakis, N.A. and J.H. Fowler. 2007. The spread of obesity in a large social network over 32 years. New England Journal of Medicine 357(4):370-379.

Cohen-Cole, E. and J.M. Fletcher. 2008a. Is obesity contagious? Social networks vs. environmental factors in the obesity epidemic. Journal of Health Economics 27(5):13821387.

Cohen-Cole, E. and J.M. Fletcher. 2008b. Detecting implausible social network effects in acne, height, and headaches: longitudinal analysis. British Medical Journal, volume 337.

Coleman, James S. 1961. The Adolescent Society: The Social Life of the Teenager and Its Impact on Education. New York: Free Press.

Conley D, J. Fletcher. 2017. The Genome Factor: What the Social Genomics Revolution Reveals about Ourselves, Our History, and the Future. Princeton University Press. 
Daw, Jonathan, Rachel Margolis, and Ashton M. Verdery. 2015. "Siblings, Friends, CourseMates, Club-Mates: How Adolescent Health Behavior Homophily Varies by Race, Class, Gender, and Health Status.” Social Science \& Medicine, 125: 32-39.

Domingue BW, Belsky DW, Harris KM, Smolen A, McQueen MB, Boardman JD. 2014. Polygenic Risk Predicts Obesity in Both White and Black Young Adults. PLoS ONE 9(7): e101596. doi:10.1371/journal.pone.0101596

Dudbridge, F. 2013. Power and predictive accuracy of polygenic risk scores. PLOS Genetics 9(3): e1003348. doi:10.1371/journal.pgen.1003348.

Eisenberg, D., Golberstein, E., Whitlock, J.L. 2014. "Peer Effects on Risky Behaviors: Evidence from College Roommate Assignments." Journal of Health Economics, 33: 126-138.

Flegal, K.M., D. Kruszon-Moran, M.D. Carroll, et al. 2016. Trends in obesity among adults in the United States, 2005 to 2014. JAMA 315(21):2284-2291.

Fletcher, JM. 2014. Peer Effects in Health Behaviors. In: Culyer, AJ (editor), Encyclopedia of Health Economics. Elseveier.

Haberstick BC, Lessem JM, McQueen MB, Boardman JD, Hopfer CJ, Smolen A, Hewitt JK. 2010. Stable genes and changing environments: body mass index across adolescence and young adulthood. Behavior Genetics. 40:495-504.

Harris, K. M.; Halpern, C. T.; Haberstick, B. C.; \& Smolen, A. 2013. The National Longitudinal Study of Adolescent Health (Add Health) sibling pairs data. Twin Research and Human Genetics, 16(1), 391-398.

Hu, F.B., 2008. Obesity Epidemiology. Oxford University Press, New York.

Institute of Medicine (IOM). 2012. Accelerating Progress in Obesity Prevention: Solving the Weight of the Nation. National Academies Press, Washington, DC.

Kaplowitz P.B. 2008. Link Between Body Fat and the Timing of Puberty. Pediatrics: 121 (Suppl 3): S208-S217.

Kling, J.R., J.B. Liebman, L.F. Katz. 2007. Experimental analysis of neighborhood effects. Econometrica 75(1):83-119.

Leibenstein, H. 1950. Bandwagan, snob and Veblen effects in the theory of consumers' demand. Quarterly Journal of Economics 64(2):183-207.

Locke, A.E. et al. 2015. Genetic studies of body mass index yield new insights for obesity biology. Nature, 518(7538): 197-206. 
Ludwig, J., Sanbonmatsu L., Gennetian L, Adam, E, Duncan, GJ et al. 2011. Neighborhoods, Obesity, and Diabetes - A Randomized Social Experiment. N Engl J Med, 365:15091519.

Manski, C.F. 1993. Identification of endogenous social effects: The reflection problem. Review of Economic Studies 60(3):531-542.

Manski, C.F. 2000. Economic analysis of social interactions. Journal of Economic Perspectives 14(3):115-136.

McQueen MB, Boardman JD, Domingue BW, Smolen A, Tabor J, Killeya-Jones L, Harris KM. 2015. The National Longitudinal Study of Adolescent to Adult Health (Add Health) Sibling Pairs Genome-Wide Data. Behavior genetics. 45(1):12-23

Mokdad, A.H., J.S. Marks, D.F. Stroup, et al. 2005. The actual causes of death in the United States, 2000. JAMA 293(3):293-294.

National Longitudinal Survey of Adolescent Health. 2017. Wave IV BMI Genetic Risk Score. http://www.cpc.unc.edu/projects/addhealth/documentation/restricteduse/datasets/GRS_B MI.pdf

$\mathrm{Ng}$, Marie, Tom Fleming, Margaret Robinson, et al. 2014. "Global, Regional, and National Prevalence of Overweight and Obesity in Children and Adults during 1980-2013: A Systematic Analysis for the Global Burden of Disease Study 2013." The Lancet 384 (9945): 766-781.

Ogden, C.L., M.D. Carroll, H.D. Lawman, et al. 2016. Trends in obesity prevalence among children and adolescents in the United States, 1988-1994 through 2013-2014. JAMA 315(21):2292-2299.

Renna, F., I.B. Grafova, N. Thakur. 2008. The effect of friends on adolescent body weight. Economics and Human Biology 6(3):377-387.

Sassi, Franco. 2010. Obesity and the Economics of Prevention: Fit not Fat. Organization for Economic Co-Operation and Development. http://www.oecd.org/els/healthsystems/obesity-and-the-economics-of-prevention-9789264084865-en.htm

Scholder, S.V.K., G.D. Smith, D.A. Lawlor, C. Propper, F. Windmeijer. 2011. Mendelian randomization: The use of genes in instrumental variable analysis. Health Economics 20(8):893-896.

Scholder, S.V.K., G.D. Smith, D.A. Lawlor, C. Propper, F. Windmeijer. 2016. Genetic markers as instrumental variables. Journal of Health Economics 45:131-148.

Silventoinen, K., B. Rokholm, J. Kaprio, TIA Sorensen. 2010. "The genetic and environmental influences on childhood obesity: a systematic review of twin and adoption studies." International Journal of Obesity, 34: 29-40. 
Smolen, A., E.A. Whitsel, J. Tabor, L.A. Killeya-Jones, et al. 2013. Add Health Wave IV Documentation: Candidate Genes.

http://www.cpc.unc.edu/projects/addhealth/documentation/guides/DNA_documentation.p df

Speliotes, E.K., C.J. Willer, S.I. Berndt, et al. 2010. Association analyses of 249,796 individuals reveal 18 new loci associated with body mass index. Nature Genetics 42(11):937-U53.

Trogdon, J.G., J. Nonnemaker, J. Pais. 2008. Peer effects in adolescent overweight. Journal of Health Economics 27(5):1388-1399.

Wang Y. 2002. Is obesity associated with earlier sexual maturation? A comparison of the association in American boys vs girls. Pediatrics. 110(5):903-910

Yakusheva, O., K.A. Kapinos, D. Eisenberg. 2014. Estimating heterogeneous and hierarchical peer effects on body weight using roommate assignments as a natural experiment. Journal of Human Resources 49(1):234-261.

Yakusheva O, Fletcher J. 2015. "Learning from Teen Childbearing Experiences of Close Friends: Evidence using Miscarriages as a Natural Experiment." Review of Economics and Statistics, 97(1): 29-43. 
Tables

Table 1: Summary statistics: Full Siblings

\begin{tabular}{|c|c|c|c|c|}
\hline & Mean & S.D. & Min. & Max. \\
\hline \multicolumn{5}{|l|}{ Outcome of Interest $(\mathrm{N}=2,311)$} \\
\hline (2) & 26.76 & 7.32 & 14.36 & 80.52 \\
\hline Obese & 0.261 & 0.439 & 0 & 1 \\
\hline \multicolumn{5}{|l|}{ Ego Characteristics $(\mathrm{N}=2,311)$} \\
\hline Genetic Risk Score (GRS) & 27.306 & 3.53 & 18 & 39 \\
\hline Male & 0.479 & 0.499 & 0 & 1 \\
\hline Age & 22.620 & 5.310 & 12 & 34 \\
\hline African-American & 0.165 & 0.371 & 0 & 1 \\
\hline Hispanic & 0.122 & 0.327 & 0 & 1 \\
\hline Other Race & 0.103 & 0.303 & 0 & 1 \\
\hline White & 0.609 & 0.488 & 0 & 1 \\
\hline married & 0.261 & 0.439 & 0 & 1 \\
\hline Less than HS & 0.273 & 0.446 & 0 & 1 \\
\hline HS grad & 0.340 & 0.474 & 0 & 1 \\
\hline less than college & 0.203 & 0.402 & 0 & 1 \\
\hline College grad & 0.142 & 0.349 & 0 & 1 \\
\hline Working Part-time & 0.380 & 0.485 & 0 & 1 \\
\hline Working Full-time & 0.505 & 0.500 & 0 & 1 \\
\hline Live with Parents & 0.487 & 0.499 & 0 & 1 \\
\hline Live with Siblings & 0.400 & 0.490 & 0 & 1 \\
\hline \multicolumn{5}{|l|}{ Alter Characteristics $(\mathrm{N}=2,311)$} \\
\hline Genetic Risk Score (GRS) & 27.304 & 3.54 & 18 & 39 \\
\hline age difference (months) & 27.128 & 12.081 & 9 & 71 \\
\hline same sex sibling & 0.585 & 0.493 & 0 & 1 \\
\hline \multicolumn{5}{|l|}{ Household Characteristics $(\mathrm{N}=2,311)$} \\
\hline $20 \mathrm{~K}<$ Income $<39 \mathrm{~K}$ & 0.206 & 0.404 & 0 & 1 \\
\hline $40 \mathrm{~K}<$ Income $<49 \mathrm{~K}$ & 0.088 & 0.283 & 0 & 1 \\
\hline $50 \mathrm{~K}<$ Income $<75 \mathrm{~K}$ & 0.173 & 0.378 & 0 & 1 \\
\hline $75 \mathrm{~K}<$ Income $<99 \mathrm{~K}$ & 0.091 & 0.287 & 0 & 1 \\
\hline $100 \mathrm{~K}<$ Income & 0.094 & 0.292 & 0 & 1 \\
\hline Parents: less than HS & 0.129 & 0.335 & 0 & 1 \\
\hline Parents: HS grad & 0.304 & 0.460 & 0 & 1 \\
\hline Parents: Less than College & 0.257 & 0.437 & 0 & 1 \\
\hline Parents: College Grad & 0.185 & 0.389 & 0 & 1 \\
\hline
\end{tabular}

Data: Add Health Waves II, III, and IV, pooled. 
Table 2: Regression results for equation (1), Full Siblings only.

A. All Waves Pooled (Wave II, III, and IV)

\begin{tabular}{|c|c|c|c|c|}
\hline & (1) & (2) & (3) & (4) \\
\hline & \multicolumn{2}{|c|}{ Obese } & \multicolumn{2}{|c|}{ BMI } \\
\hline Mean of DV & & & & \\
\hline BMI Risk Score of alter & & $\begin{array}{c}0.0097 * * \\
{[0.0040]}\end{array}$ & & $\begin{array}{c}0.1560^{* *} \\
{[0.0671]}\end{array}$ \\
\hline BMI Risk Score of ego & $\begin{array}{l}0.0187 \text { *** } \\
{[0.0039]}\end{array}$ & $\begin{array}{c}0.0136^{* * *} \\
{[0.0041]}\end{array}$ & $\begin{array}{c}0.3961 * * * \\
{[0.0672]}\end{array}$ & $\begin{array}{c}0.3135^{* * *} \\
{[0.0691]}\end{array}$ \\
\hline Observations & 2,311 & 2,311 & 2,311 & 2,311 \\
\hline R-squared & 0.124 & 0.128 & 0.215 & 0.219 \\
\hline
\end{tabular}

Notes: Robust standard errors in brackets. Demographic variables controlled for are age, sex, race, whether the respondent lives with parents, whether the siblings live together, total household income, the respondent's highest grade completed, marital status, employment status, and parental educational attainment. The reported number for Obese outcome is OLS coefficient. $* * * p<0.01,{ }^{* *} \mathrm{p}<0.05,{ }^{*} \mathrm{p}<0.1$

\section{B. Wave II}

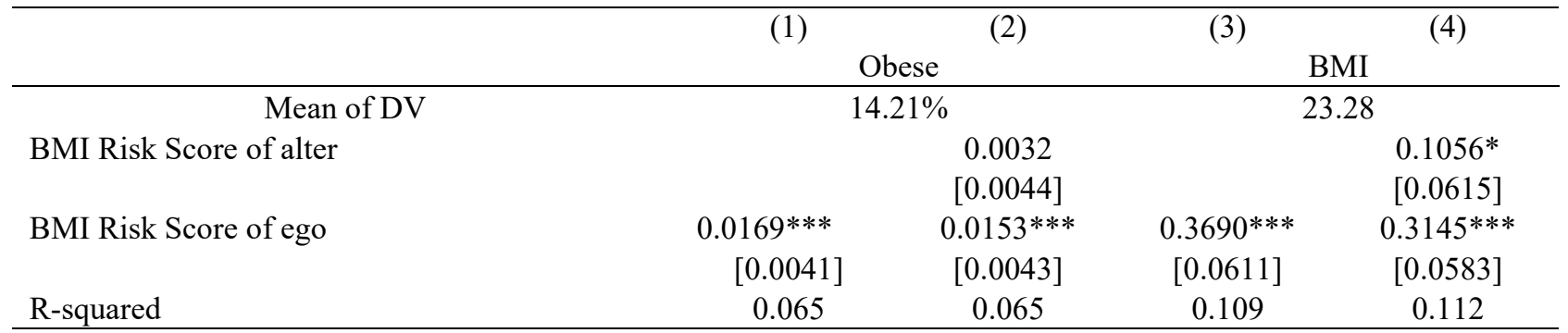

Notes: Robust standard errors in brackets. Demographic variables controlled for are age, sex, race, whether the respondent lives with parents, whether the siblings live together, total household income, the respondent's highest grade completed, marital status, employment status, and parental educational attainment. The reported number for Obese outcome is OLS coefficient. ${ }^{* * *} \mathrm{p}<0.01,{ }^{* *} \mathrm{p}<0.05,{ }^{*} \mathrm{p}<0.1$

\section{Wave III}

\begin{tabular}{|c|c|c|c|c|}
\hline & (1) & (2) & (3) & (4) \\
\hline & \multicolumn{2}{|c|}{ Obese } & \multicolumn{2}{|r|}{ BMI } \\
\hline Mean of DV & & & & 26.91 \\
\hline BMI Risk Score of alter & & $\begin{array}{c}0.0147 * * * \\
{[0.0051]}\end{array}$ & & $\begin{array}{c}0.2146^{* * *} * \\
{[0.0748]}\end{array}$ \\
\hline BMI Risk Score of ego & $\begin{array}{r}0.0147 * * * \\
{[0.0054]}\end{array}$ & $\begin{array}{c}0.0068 \\
{[0.0055]}\end{array}$ & $\begin{array}{c}0.3775 * * * \\
{[0.0875]}\end{array}$ & $\begin{array}{c}0.2615 * * * \\
{[0.0855]}\end{array}$ \\
\hline R-squared & 0.080 & 0.090 & 0.109 & 0.118 \\
\hline
\end{tabular}

Notes: Robust standard errors in brackets. Demographic variables controlled for are age, sex, race, whether the respondent lives with parents, whether the siblings live together, total household income, the respondent's highest grade completed, marital status, employment status, and parental educational attainment. The reported number for Obese outcome is OLS coefficient. $* * * p<0.01,{ }^{* *} \mathrm{p}<0.05,{ }^{*} \mathrm{p}<0.1$ 
D. Wave IV

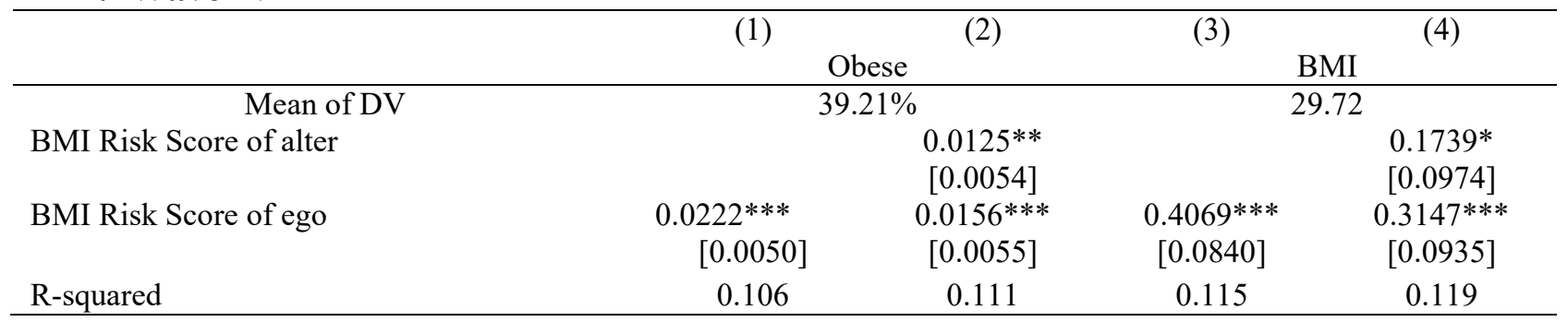

Notes: Robust standard errors in brackets. Demographic variables controlled for are age, sex, race, whether the respondent lives with parents, whether the siblings live together, total household income, the respondent's highest grade completed, marital status, employment status, and parental educational attainment. The reported number for Obese outcome is OLS coefficient. ${ }^{* * *} \mathrm{p}<0.01,{ }^{*} \mathrm{p}<0.05,{ }^{*} \mathrm{p}<0.1$ 
Table 3: Regression Results for Subgroup analysis, All Waves Pooled

\section{A. When Ego is old vs. When Ego is young}

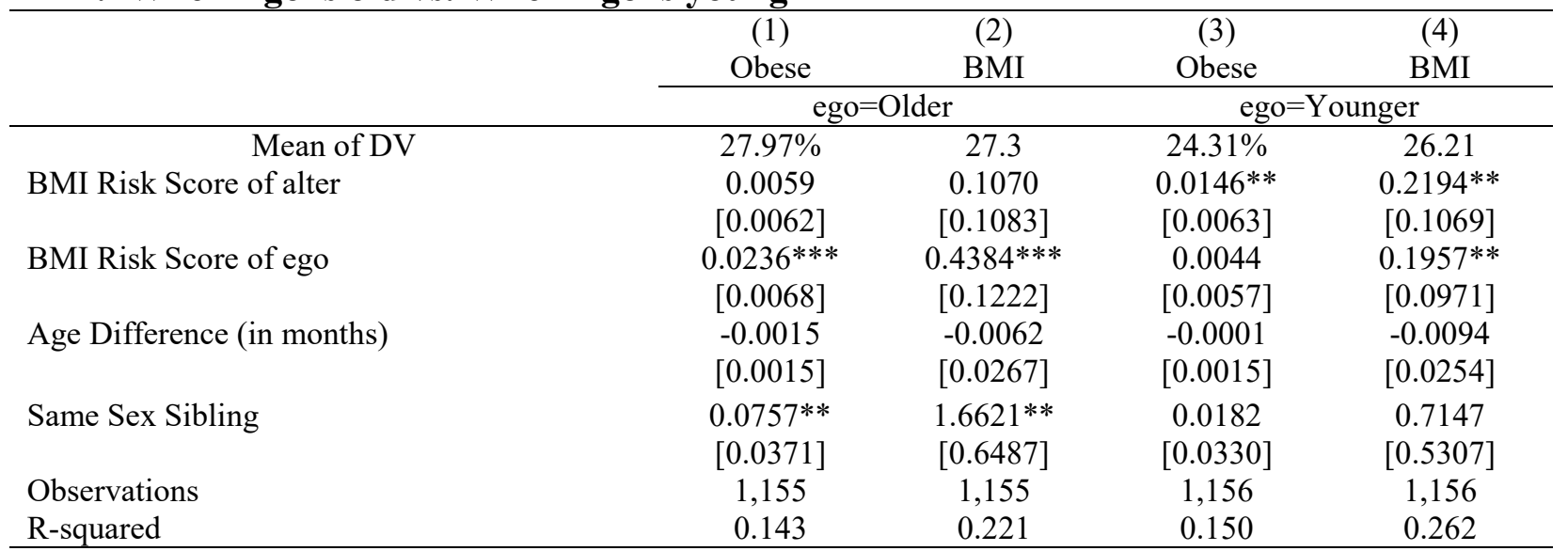

Test for equality of coefficients on BMI Risk

Score of alter across the two subgroups:

$\begin{aligned} \text { Outcome: Obese } & \text { P-value }=0.3503 \\ \text { Outcome: BMI } & \text { P-value }=0.4979\end{aligned}$

Notes: Robust standard errors in brackets. Demographic variables controlled for are age, sex, race, whether the respondent lives with parents, whether the siblings live together, total household income, the respondent's highest grade completed, marital status, employment status, and parental educational attainment. The reported number for Obese outcome is OLS coefficient. ${ }^{* * *} \mathrm{p}<0.01,{ }^{* *} \mathrm{p}<0.05,{ }^{*} \mathrm{p}<0.1$

\section{B. Same-sex Sibling vs. Different-sex Sibling}

\begin{tabular}{|c|c|c|c|c|}
\hline & $\begin{array}{c}(1) \\
\text { Obese } \\
\end{array}$ & $\begin{array}{c}(2) \\
\text { BMI }\end{array}$ & $\begin{array}{c}(3) \\
\text { Obese } \\
\end{array}$ & $\begin{array}{c}(4) \\
\text { BMI }\end{array}$ \\
\hline & \multicolumn{2}{|c|}{ Same-sex Siblings } & \multicolumn{2}{|c|}{ Different-sex Siblings } \\
\hline Mean of DV & $27.37 \%$ & 27.09 & $24.40 \%$ & 26.28 \\
\hline BMI Risk Score of alter & $\begin{array}{l}0.0100 * * \\
{[0.0047]}\end{array}$ & $\begin{array}{l}0.1459 * \\
{[0.0838]}\end{array}$ & $\begin{array}{c}0.0098 \\
{[0.0069]}\end{array}$ & $\begin{array}{l}0.1859 * \\
{[0.1105]}\end{array}$ \\
\hline BMI Risk Score of ego & $\begin{array}{c}0.0136^{* * *} \\
{[0.0049]}\end{array}$ & $\begin{array}{c}0.3433 * * * \\
{[0.0836]}\end{array}$ & $\begin{array}{l}0.0157^{* *} \\
{[0.0074]}\end{array}$ & $\begin{array}{c}0.3271 * * * \\
{[0.1235]}\end{array}$ \\
\hline Age Difference (in months) & $\begin{array}{l}-0.0026^{*} \\
{[0.0014]}\end{array}$ & $\begin{array}{l}-0.0460^{*} \\
{[0.0265]}\end{array}$ & $\begin{array}{c}0.0018 \\
{[0.0017]}\end{array}$ & $\begin{array}{c}0.0455 \\
{[0.0296]}\end{array}$ \\
\hline $\begin{array}{l}\text { Observations } \\
\text { R-squared }\end{array}$ & $\begin{array}{l}1,352 \\
0.155\end{array}$ & $\begin{array}{l}1,352 \\
0.243\end{array}$ & $\begin{array}{c}959 \\
0.147\end{array}$ & $\begin{array}{c}959 \\
0.239\end{array}$ \\
\hline $\begin{array}{l}\text { Test for equality of coefficients on BMI Risk } \\
\text { Score of alter across the two subgroups: } \\
\text { Outcome: Obese } \\
\text { Outcome: BMI }\end{array}$ & & $\begin{array}{l}\text { P-va } \\
\text { P-va }\end{array}$ & $\begin{array}{l}9765 \\
7698\end{array}$ & \\
\hline
\end{tabular}

Notes: Robust standard errors in brackets. Demographic variables controlled for are age, sex, race, whether the respondent lives with parents, whether the siblings live together, total household income, the respondent's highest grade completed, marital status, employment status, and parental educational attainment. The reported number for Obese outcome is OLS coefficient. *** $\mathrm{p}<0.01, * * \mathrm{p}<0.05,{ }^{*} \mathrm{p}<0.1$ 
C. When Ego $=$ Female vs. When Ego=Male

\begin{tabular}{|c|c|c|c|c|}
\hline & $\begin{array}{l}(1) \\
\text { Obese }\end{array}$ & $\begin{array}{c}(2) \\
\text { BMI }\end{array}$ & $\begin{array}{c}(3) \\
\text { Obese }\end{array}$ & $\begin{array}{c}(4) \\
\text { BMI }\end{array}$ \\
\hline & \multicolumn{2}{|c|}{$\mathrm{eg}_{\mathrm{o}}=$ Female } & \multicolumn{2}{|c|}{ ego $=$ Male } \\
\hline Mean of DV & $27.39 \%$ & 26.78 & $24.77 \%$ & 26.72 \\
\hline BMI Risk Score of alter & $\begin{array}{l}0.0106^{*} \\
{[0.0054]}\end{array}$ & $\begin{array}{l}0.1555^{*} \\
{[0.0892]}\end{array}$ & $\begin{array}{c}0.0086 \\
{[0.0060]}\end{array}$ & $\begin{array}{c}0.1476 \\
{[0.1060]}\end{array}$ \\
\hline BMI Risk Score of ego & $\begin{array}{l}0.0122 * * \\
{[0.0055]}\end{array}$ & $\begin{array}{c}0.2880 * * * \\
{[0.0960]}\end{array}$ & $\begin{array}{l}0.0148 * * \\
{[0.0064]}\end{array}$ & $\begin{array}{c}0.3333 * * * \\
{[0.1067]}\end{array}$ \\
\hline Age Difference (in months) & $\begin{array}{c}-0.0005 \\
{[0.0016]}\end{array}$ & $\begin{array}{c}0.0030 \\
{[0.0276]}\end{array}$ & $\begin{array}{c}-0.0008 \\
{[0.0015]}\end{array}$ & $\begin{array}{c}-0.0128 \\
{[0.0258]}\end{array}$ \\
\hline Same Sex Sibling & $\begin{array}{c}0.0215 \\
{[0.0374]}\end{array}$ & $\begin{array}{c}0.9527 \\
{[0.6577]}\end{array}$ & $\begin{array}{c}0.0427 \\
{[0.0365]}\end{array}$ & $\begin{array}{c}0.8296 \\
{[0.6122]}\end{array}$ \\
\hline $\begin{array}{l}\text { Observations } \\
\text { R-squared }\end{array}$ & $\begin{array}{l}1,205 \\
0.165\end{array}$ & $\begin{array}{l}1,205 \\
0.262\end{array}$ & $\begin{array}{l}1,106 \\
0.133\end{array}$ & $\begin{array}{l}1,106 \\
0.228\end{array}$ \\
\hline $\begin{array}{l}\text { Test for equality of coefficients on BMI Risk } \\
\text { Score of alter across the two subgroups: } \\
\text { Outcome: Obese } \\
\text { Outcome: BMI }\end{array}$ & & $\begin{array}{l}\text { P-val } \\
\text { P-val }\end{array}$ & $\begin{array}{l}8057 \\
9555\end{array}$ & \\
\hline
\end{tabular}

Notes: Robust standard errors in brackets. Demographic variables controlled for are age, sex, race, whether the respondent lives with parents, whether the siblings live together, total household income, the respondent's highest grade completed, marital status, employment status, and parental educational attainment. The reported number for Obese outcome is OLS coefficient. $* * * \mathrm{p}<0.01, * * \mathrm{p}<0.05, * \mathrm{p}<0.1$

\section{When Ego=Non-white vs. When Ego=White}

\begin{tabular}{|c|c|c|c|c|}
\hline & $\begin{array}{c}(1) \\
\text { Obese }\end{array}$ & $\begin{array}{c}(2) \\
\text { BMI }\end{array}$ & $\begin{array}{c}(3) \\
\text { Obese }\end{array}$ & $\begin{array}{c}(4) \\
\mathrm{BMI}\end{array}$ \\
\hline & \multicolumn{2}{|c|}{ ego=Non-white } & \multicolumn{2}{|c|}{ ego=White } \\
\hline Mean of DV & $28.65 \%$ & 27.17 & $24.52 \%$ & 26.49 \\
\hline BMI Risk Score of alter & $\begin{array}{l}0.0170^{* *} \\
{[0.0067]}\end{array}$ & $\begin{array}{c}0.3213^{* * *} \\
{[0.1190]}\end{array}$ & $\begin{array}{c}0.0068 \\
{[0.0048]}\end{array}$ & $\begin{array}{c}0.0907 \\
{[0.0796]}\end{array}$ \\
\hline BMI Risk Score of ego & $\begin{array}{c}0.0063 \\
{[0.0075]}\end{array}$ & $\begin{array}{l}0.2609^{*} \\
{[0.1348]}\end{array}$ & $\begin{array}{c}0.0175^{* * *} \\
{[0.0048]}\end{array}$ & $\begin{array}{c}0.3405^{* * *} \\
{[0.0784]}\end{array}$ \\
\hline Age Difference (in months) & $\begin{array}{l}-0.0008 \\
{[0.0017]}\end{array}$ & $\begin{array}{c}0.0036 \\
{[0.0305]}\end{array}$ & $\begin{array}{l}-0.0006 \\
{[0.0014]}\end{array}$ & $\begin{array}{l}-0.0142 \\
{[0.0245]}\end{array}$ \\
\hline Same Sex Sibling & $\begin{array}{c}0.0581 \\
{[0.0456]}\end{array}$ & $\begin{array}{c}1.2528 \\
{[0.8076]}\end{array}$ & $\begin{array}{c}0.0202 \\
{[0.0347]}\end{array}$ & $\begin{array}{c}0.6613 \\
{[0.6029]}\end{array}$ \\
\hline $\begin{array}{l}\text { Observations } \\
\text { R-squared }\end{array}$ & $\begin{array}{c}904 \\
0.173\end{array}$ & $\begin{array}{c}904 \\
0.272\end{array}$ & $\begin{array}{l}1,407 \\
0.131\end{array}$ & $\begin{array}{l}1,407 \\
0.227\end{array}$ \\
\hline $\begin{array}{l}\text { Test for equality of coefficients on BMI Risk } \\
\text { Score of alter across the two subgroups: }\end{array}$ & & & & \\
\hline $\begin{array}{r}\text { Outcome: Obese } \\
\text { Outcome: BMI }\end{array}$ & & $\begin{array}{l}\text { P-val } \\
\text { P-val }\end{array}$ & $\begin{array}{l}.1992 \\
.0964\end{array}$ & \\
\hline
\end{tabular}

Notes: Robust standard errors in brackets. Demographic variables controlled for are age, sex, race, whether the respondent lives with parents, whether the siblings live together, total household income, the respondent's highest grade completed, marital status, employment status, and parental educational attainment. The reported number for Obese outcome is OLS coefficient. $* * * p<0.01, * * p<0.05, * p<0.1$ 


\section{E. When Ego's BMI Risk Score>Average vs. Ego's BMI Risk Score $<$ Average}

\begin{tabular}{|c|c|c|c|c|}
\hline & $\begin{array}{c}(1) \\
\text { Obese }\end{array}$ & $\begin{array}{c}(2) \\
\text { BMI }\end{array}$ & $\begin{array}{c}(3) \\
\text { Obese }\end{array}$ & $\begin{array}{c}(4) \\
\text { BMI }\end{array}$ \\
\hline & \multicolumn{2}{|c|}{ Ego's GRS>Average } & \multicolumn{2}{|c|}{ Ego's GRS<Average } \\
\hline Mean of DV & $30.89 \%$ & 27.8 & $21.79 \%$ & 25.8 \\
\hline \multirow[t]{2}{*}{ BMI Risk Score of alter } & 0.0060 & 0.0713 & $0.0133 * *$ & $0.2242 * *$ \\
\hline & {$[0.0069]$} & {$[0.1192]$} & {$[0.0057]$} & {$[0.0980]$} \\
\hline \multirow[t]{2}{*}{ BMI Risk Score of ego } & $0.0296 * *$ & $0.5934 * * *$ & -0.0016 & 0.0790 \\
\hline & {$[0.0121]$} & {$[0.1949]$} & {$[0.0073]$} & {$[0.1231]$} \\
\hline \multirow[t]{2}{*}{ Age Difference (in months) } & -0.0013 & -0.0157 & 0.0002 & 0.0086 \\
\hline & {$[0.0016]$} & {$[0.0284]$} & {$[0.0014]$} & {$[0.0251]$} \\
\hline \multirow[t]{2}{*}{ Same Sex Sibling } & 0.0295 & 0.9453 & $0.0633^{*}$ & $1.2408 * *$ \\
\hline & {$[0.0407]$} & {$[0.7213]$} & {$[0.0339]$} & {$[0.5763]$} \\
\hline Observations & 1,104 & 1,104 & 1,207 & 1,207 \\
\hline R-squared & 0.130 & 0.207 & 0.147 & 0.256 \\
\hline \multicolumn{5}{|l|}{ Test for equality of coefficients on BMI Risk } \\
\hline Outcome: Obese & \multirow{2}{*}{\multicolumn{4}{|c|}{$\begin{array}{l}\text { P-value }=0.4382 \\
\text { P-value }=0.3538\end{array}$}} \\
\hline Outcome: BMI & & & & \\
\hline
\end{tabular}

Notes: Robust standard errors in brackets. Demographic variables controlled for are age, sex, race, whether the respondent lives with parents, whether the siblings live together, total household income, the respondent's highest grade completed, marital status, employment status, and parental educational attainment. The reported number for Obese outcome is OLS coefficient. ${ }^{* * *} \mathrm{p}<0.01,{ }^{* *} \mathrm{p}<0.05,{ }^{*} \mathrm{p}<0.1$ 
Table 4: Regression results for equation (1), Heterogeneous Effects by Alter's GRS being Top $20 \%$ or Bottom 20\%, Full Siblings, All Waves Pooled (Wave II, III, and IV).

\begin{tabular}{lcc}
\hline & $(1)$ & $(2)$ \\
VARIABLES & Obese & BMI \\
\hline & $0.0152^{* *}$ & 0.1542 \\
BMI Risk Score of alter & {$[0.0077]$} & {$[0.1287]$} \\
& $0.0136^{* * *}$ & $0.3176^{* * *}$ \\
BMI Risk Score of ego & {$[0.0041]$} & {$[0.0699]$} \\
& {$[0.7128]$} & {$[10.7351]$} \\
Alter GRS Bottom 20\% & 0.1265 & -3.9908 \\
& {$[0.4542]$} & {$[7.4948]$} \\
BMI Risk Score of alter*Alter GRS Top 20\% & 0.0134 & 0.3547 \\
& {$[0.0225]$} & {$[0.3386]$} \\
BMI Risk Score of alter*Alter GRS Bottom 20\% & -0.0021 & 0.2288 \\
& {$[0.0206]$} & {$[0.3398]$} \\
Observations & 2,311 & 2,311 \\
R-squared & 0.133 & 0.228 \\
\hline Notes: Robust standard errors in brackets. Demographic variables controlled for are age, \\
sex, race, whether the respondent lives with parents, whether the siblings live together, \\
total household income, the respondent's highest grade completed, marital status, \\
employment status, and parental educational attainment. The reported number for Obese \\
outcome is OLS coefficient. ${ }^{* * *} \mathrm{p}<0.01, * *$ p $<0.05,{ }^{*}$ p $<0.1$
\end{tabular}


Table 5: Regression results for equation (1), DZ Twins.

\section{A. All Waves Pooled (Wave II, III, and IV)}

\begin{tabular}{lcccc}
\hline & $(1)$ & $(2)$ & $(3)$ & $(4)$ \\
& \multicolumn{2}{c}{ Obese } & \multicolumn{2}{c}{ BMI } \\
\hline Mean of DV & \multicolumn{2}{c}{$17.69 \%$} & \multicolumn{2}{c}{25.12} \\
BMI Risk Score of alter & \multicolumn{2}{c}{-0.0055} & & -0.0735 \\
& \multicolumn{2}{c}{$[0.0072]$} & & {$[0.1213]$} \\
BMI Risk Score of ego & $0.0125^{*}$ & $0.0152^{* *}$ & $0.1933^{*}$ & $0.2291^{* *}$ \\
& {$[0.0068]$} & {$[0.0071]$} & {$[0.1152]$} & {$[0.1133]$} \\
R-squared & 0.117 & 0.119 & 0.205 & 0.206 \\
\hline
\end{tabular}

Notes: Robust standard errors in brackets. Demographic variables controlled for are age, sex, race, whether the respondent lives with parents, whether the siblings live together, total household income, the respondent's highest grade completed, marital status, employment status, and parental educational attainment. The reported number for Obese outcome is OLS coefficient. ${ }^{* * *} \mathrm{p}<0.01,{ }^{* *} \mathrm{p}<0.05,{ }^{*} \mathrm{p}<0.1$

\section{B. Wave II}

\begin{tabular}{|c|c|c|c|c|}
\hline & (1) & (2) & (3) & (4) \\
\hline & \multicolumn{2}{|c|}{ Obese } & \multicolumn{2}{|c|}{ BMI } \\
\hline Mean of DV & & & & \\
\hline BMI Risk Score of alter & & $\begin{array}{c}-0.0006 \\
{[0.0063]}\end{array}$ & & $\begin{array}{c}-0.0345 \\
{[0.0997]}\end{array}$ \\
\hline BMI Risk Score of ego & $\begin{array}{c}0.0136^{* *} \\
{[0.0066]}\end{array}$ & $\begin{array}{l}0.0139 * * \\
{[0.0065]}\end{array}$ & $\begin{array}{c}0.0953 \\
{[0.0953]}\end{array}$ & $\begin{array}{c}0.1125 \\
{[0.0937]}\end{array}$ \\
\hline R-squared & 0.083 & 0.083 & 0.111 & 0.111 \\
\hline
\end{tabular}

Notes: Robust standard errors in brackets. Demographic variables controlled for are age, sex, race, whether the respondent lives with parents, whether the siblings live together, total household income, the respondent's highest grade completed, marital status, employment status, and parental educational attainment. The reported number for Obese outcome is OLS coefficient. ${ }^{* * *} \mathrm{p}<0.01,{ }^{* *} \mathrm{p}<0.05,{ }^{*} \mathrm{p}<0.1$

\section{Wave III}

\begin{tabular}{lcccc}
\hline & $(1)$ & $(2)$ & $(3)$ & $(4)$ \\
& \multicolumn{2}{c}{ Obese } & \multicolumn{2}{c}{ BMI } \\
\hline Mean of DV & \multicolumn{2}{c}{$15.25 \%$} & \multicolumn{2}{c}{25.11} \\
BMI Risk Score of alter & \multicolumn{2}{c}{-0.0033} & & -0.0530 \\
& \multicolumn{2}{c}{$[0.0099]$} & & {$[0.1447]$} \\
BMI Risk Score of ego & $0.0153^{*}$ & $0.0168^{*}$ & 0.2099 & $0.2329^{*}$ \\
& {$[0.0084]$} & {$[0.0091]$} & {$[0.1304]$} & {$[0.1283]$} \\
R-squared & 0.161 & 0.162 & 0.155 & 0.156 \\
\hline
\end{tabular}

Notes: Robust standard errors in brackets. Demographic variables controlled for are age, sex, race, whether the respondent lives with parents, whether the siblings live together, total household income, the respondent's highest grade completed, marital status, employment status, and parental educational attainment. The reported number for Obese outcome is OLS coefficient. ${ }^{* * *} \mathrm{p}<0.01,{ }^{* *} \mathrm{p}<0.05,{ }^{*} \mathrm{p}<0.1$ 


\section{Wave IV}

\begin{tabular}{|c|c|c|c|c|}
\hline & (1) & (2) & (3) & (4) \\
\hline VARIABLES & \multicolumn{2}{|c|}{ Obese } & \multicolumn{2}{|c|}{ BMI } \\
\hline Mean of DV & \multicolumn{2}{|c|}{$28.08 \%$} & \multicolumn{2}{|c|}{27.7} \\
\hline BMI Risk Score of alter & & $\begin{array}{c}-0.0138 \\
{[0.0106]}\end{array}$ & & $\begin{array}{c}-0.1736 \\
{[0.1454]}\end{array}$ \\
\hline BMI Risk Score of ego & $\begin{array}{l}0.0062 \\
{[0.0096]}\end{array}$ & $\begin{array}{c}0.0135 \\
{[0.0098]}\end{array}$ & $\begin{array}{c}0.1596 \\
{[0.1467]}\end{array}$ & $\begin{array}{l}0.2504 * \\
{[0.1423]}\end{array}$ \\
\hline R-squared & 0.162 & 0.168 & 0.191 & 0.195 \\
\hline
\end{tabular}

Notes: Robust standard errors in brackets. Demographic variables controlled for are age, sex, race, whether the respondent lives with parents, whether the siblings live together, total household income, the respondent's highest grade completed, marital status, employment status, and parental educational attainment. The reported number for Obese outcome is OLS coefficient. ${ }^{* * *} \mathrm{p}<0.01,{ }^{* *} \mathrm{p}<0.05,{ }^{*} \mathrm{p}<0.1$ 
Table 6: Regression results for equation (1), Half Siblings and Non-Related Siblings.

\section{A. All Waves Pooled (Wave II, III, and IV)}

\begin{tabular}{|c|c|c|c|c|}
\hline & (1) & (2) & (3) & (4) \\
\hline & \multicolumn{2}{|c|}{ Obese } & \multicolumn{2}{|r|}{ BMI } \\
\hline Mean of DV & \multicolumn{2}{|c|}{$28.79 \%$} & \multicolumn{2}{|r|}{27.47} \\
\hline BMI Risk Score of alter & & $\begin{array}{c}-0.0217^{* *} \\
{[0.0094]}\end{array}$ & & $\begin{array}{c}-0.4651^{* * *} \\
{[0.1507]}\end{array}$ \\
\hline BMI Risk Score of ego & 0.0127 & 0.0167 & 0.2983 & $0.3843^{* *}$ \\
\hline & [0.0125] & {$[0.0121]$} & {$[0.1794]$} & {$[0.1692]$} \\
\hline R-squared & 0.152 & 0.168 & 0.303 & 0.326 \\
\hline
\end{tabular}

Notes: Robust standard errors in brackets. Demographic variables controlled for are age, sex, race, whether the respondent lives with parents, whether the siblings live together, total household income, the respondent's highest grade completed, marital status, employment status, and parental educational attainment. The reported number for Obese outcome is OLS coefficient. *** $\mathrm{p}<0.01, * * \mathrm{p}<0.05,{ }^{*} \mathrm{p}<0.1$

\section{B. Wave II}

\begin{tabular}{|c|c|c|c|c|}
\hline & (1) & (2) & (3) & (4) \\
\hline & \multicolumn{2}{|c|}{ Obese } & \multicolumn{2}{|r|}{ BMI } \\
\hline Mean of DV & & & & 23.81 \\
\hline BMI Risk Score of alter & & $\begin{array}{c}-0.0250^{* *} \\
{[0.0109]}\end{array}$ & & $\begin{array}{c}-0.3527^{* *} \\
{[0.1458]}\end{array}$ \\
\hline BMI Risk Score of ego & $\begin{array}{l}0.0145 \\
\quad[0.0125]\end{array}$ & $\begin{array}{c}0.0177 \\
{[0.0124]}\end{array}$ & $\begin{array}{c}0.2761 \\
{[0.1714]}\end{array}$ & $\begin{array}{l}0.3206^{*} \\
{[0.1697]}\end{array}$ \\
\hline R-squared & 0.110 & 0.142 & 0.190 & 0.219 \\
\hline
\end{tabular}

Notes: Robust standard errors in brackets. Demographic variables controlled for are age, sex, race, whether the respondent lives with parents, whether the siblings live together, total household income, the respondent's highest grade completed, marital status, employment status, and parental educational attainment. The reported number for Obese outcome is OLS coefficient. $* * * p<0.01, * * p<0.05, * p<0.1$

\section{Wave III}

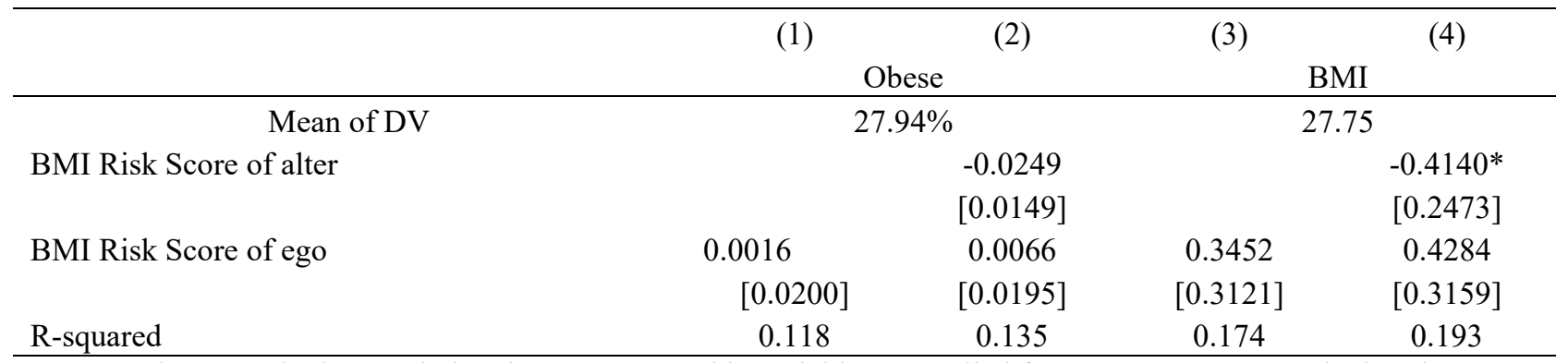

Notes: Robust standard errors in brackets. Demographic variables controlled for are age, sex, race, whether the respondent lives with parents, whether the siblings live together, total household income, the respondent's highest grade completed, marital status, employment status, and parental educational attainment. The reported number for Obese outcome is OLS coefficient. ${ }^{* * *} \mathrm{p}<0.01,{ }^{* *} \mathrm{p}<0.05,{ }^{*} \mathrm{p}<0.1$ 


\section{Wave IV}

\begin{tabular}{|c|c|c|c|c|}
\hline \multirow[t]{3}{*}{ 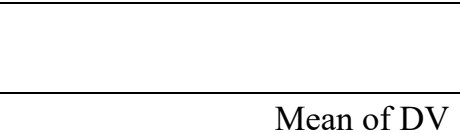 } & (1) & $(2)$ & (3) & (4) \\
\hline & \multicolumn{2}{|c|}{ Obese } & \multicolumn{2}{|r|}{ BMI } \\
\hline & \multicolumn{2}{|c|}{$41.20 \%$} & \multicolumn{2}{|r|}{30.7} \\
\hline BMI Risk Score of alter & & $\begin{array}{l}-0.0200 \\
{[0.0125]}\end{array}$ & & $\begin{array}{c}-0.6368 * * * \\
{[0.2041]}\end{array}$ \\
\hline BMI Risk Score of ego & $\begin{array}{l}0.0056 \\
{[0.0153]}\end{array}$ & $\begin{array}{c}0.0093 \\
{[0.0150]}\end{array}$ & $\begin{array}{c}0.1726 \\
{[0.2397]}\end{array}$ & $\begin{array}{c}0.2879 \\
{[0.2177]}\end{array}$ \\
\hline R-squared & 0.214 & 0.225 & 0.296 & 0.327 \\
\hline
\end{tabular}

Notes: Robust standard errors in brackets. Demographic variables controlled for are age, sex, race, whether the respondent lives with parents, whether the siblings live together, total household income, the respondent's highest grade completed, marital status, employment status, and parental educational attainment. The reported number for Obese outcome is OLS coefficient. ${ }^{* * *} \mathrm{p}<0.01,{ }^{* *} \mathrm{p}<0.05,{ }^{*} \mathrm{p}<0.1$ 
Appendix Table 1: Balance table comparing respondent and household characteristics by whether respondent has BMI risk score or not. Add Health, Wave II

\begin{tabular}{|c|c|c|c|c|}
\hline & $\begin{array}{l}\text { BMI Score Missing } \\
(\mathrm{n}=4,388)\end{array}$ & $\begin{array}{l}\text { BMI Score Reported } \\
(\mathrm{n}=1,283)\end{array}$ & Difference & T-Statistics \\
\hline \multicolumn{5}{|l|}{ Respondents' Characteristics } \\
\hline Boy & 0.49 & 0.47 & -0.02 & 1.04 \\
\hline Age & 16.51 & 16.40 & $-0.11^{* *}$ & 2.02 \\
\hline African-American & 0.23 & 0.30 & $0.07^{* * *}$ & 4.92 \\
\hline Hispanic & 0.17 & 0.11 & $-0.05 * * *$ & 4.58 \\
\hline Other Race & 0.11 & 0.07 & $-0.04 * * *$ & 3.95 \\
\hline White & 0.49 & 0.51 & 0.02 & 1.41 \\
\hline Live with Parents & 0.88 & 0.89 & $0.01^{*}$ & 1.83 \\
\hline BMI & 22.91 & 23.17 & 0.25 & 1.58 \\
\hline Obese & 0.13 & 0.14 & 0.01 & 0.98 \\
\hline \multicolumn{5}{|l|}{ Household Characteristics } \\
\hline $20 \mathrm{~K}<$ Income $<39 \mathrm{~K}$ & 0.22 & 0.24 & 0.02 & 1.56 \\
\hline $40 \mathrm{~K}<$ Income $<49 \mathrm{~K}$ & 0.09 & 0.07 & $-0.02 * * *$ & 3.02 \\
\hline $50 \mathrm{~K}<$ Income $<75 \mathrm{~K}$ & 0.18 & 0.17 & -0.01 & 1.22 \\
\hline $75 \mathrm{~K}<$ Income $<99 \mathrm{~K}$ & 0.05 & 0.05 & 0.00 & 0.51 \\
\hline $100 \mathrm{~K}<$ Income & 0.04 & 0.05 & $0.01^{*}$ & 1.69 \\
\hline Parents married & 0.60 & 0.59 & -0.01 & 0.94 \\
\hline Parents: less than HS & 0.17 & 0.14 & $-0.03 * *$ & 2.20 \\
\hline Parents: HS grad & 0.24 & 0.30 & $0.06 * * *$ & 4.52 \\
\hline Parents: Less than College & 0.26 & 0.27 & 0.01 & 0.92 \\
\hline Parents: College Grad & 0.20 & 0.17 & $-0.03 * *$ & 2.40 \\
\hline Parents: employed & 0.49 & 0.48 & -0.01 & -0.69 \\
\hline
\end{tabular}

Notes: If BMI risk score is missing for one or both of the sibling pair, then the sibling pair is assumed to have missing BMI risk score. 
Appendix Table 2: Summary statistics: Half Siblings and Non-Related Siblings

\begin{tabular}{|c|c|c|c|c|}
\hline & Mean & sd & $\min$ & $\max$ \\
\hline \multicolumn{5}{|l|}{ Outcome of Interest $(\mathrm{N}=521)$} \\
\hline 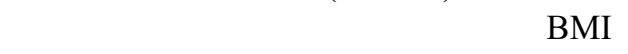 & 27.47 & 7.98 & 15.66 & 64.9 \\
\hline Obese & 0.288 & 0.453 & 0 & 1 \\
\hline \multicolumn{5}{|l|}{ Respondents' Characteristics (N=521) } \\
\hline Genetic Risk Score (GRS) & 26.22 & 2.81 & 17 & 34 \\
\hline Boy & 0.397 & 0.489 & 0 & 1 \\
\hline Age & 21.998 & 5.503 & 12 & 33 \\
\hline African-American & 0.919 & 0.273 & 0 & 1 \\
\hline Hispanic & 0.044 & 0.206 & 0 & 1 \\
\hline Other Race & 0.009 & 0.097 & 0 & 1 \\
\hline White & 0.027 & 0.162 & 0 & 1 \\
\hline married & 0.165 & 0.372 & 0 & 1 \\
\hline Less than HS & 0.395 & 0.489 & 0 & 1 \\
\hline HS grad & 0.289 & 0.454 & 0 & 1 \\
\hline less than college & 0.228 & 0.420 & 0 & 1 \\
\hline College grad & 0.029 & 0.165 & 0 & 1 \\
\hline Working Part-time & 0.317 & 0.466 & 0 & 1 \\
\hline Working Full-time & 0.437 & 0.497 & 0 & 1 \\
\hline Live with Parents & 0.414 & 0.493 & 0 & 1 \\
\hline Live with Siblings & 0.184 & 0.388 & 0 & 1 \\
\hline \multicolumn{5}{|l|}{ Sibling Characteristics $(\mathrm{N}=521)$} \\
\hline Genetic Risk Score (GRS) & 26.28 & 2.83 & 17 & 34 \\
\hline age difference (months) & 26.508 & 16.586 & 1 & 78 \\
\hline same sex sibling & 0.529 & 0.499 & 0 & 1 \\
\hline \multicolumn{5}{|l|}{ Household Characteristics $(\mathrm{N}=521)$} \\
\hline $20 \mathrm{~K}<$ Income $<39 \mathrm{~K}$ & 0.230 & 0.421 & 0 & 1 \\
\hline $40 \mathrm{~K}<$ Income $<49 \mathrm{~K}$ & 0.054 & 0.226 & 0 & 1 \\
\hline $50 \mathrm{~K}<$ Income $<75 \mathrm{~K}$ & 0.088 & 0.284 & 0 & 1 \\
\hline $75 \mathrm{~K}<$ Income $<99 \mathrm{~K}$ & 0.021 & 0.144 & 0 & 1 \\
\hline $100 \mathrm{~K}<$ Income & 0.019 & 0.137 & 0 & 1 \\
\hline Parents: less than HS & 0.330 & 0.471 & 0 & 1 \\
\hline Parents: HS grad & 0.282 & 0.450 & 0 & 1 \\
\hline Parents: Less than College & 0.246 & 0.431 & 0 & 1 \\
\hline Parents: College Grad & 0.073 & 0.260 & 0 & 1 \\
\hline
\end{tabular}


Appendix Table 3: Regression results for equation (1), Full Siblings only. Wave I Included.

\section{A. All Waves Pooled (Wave I, II, III, and IV)}

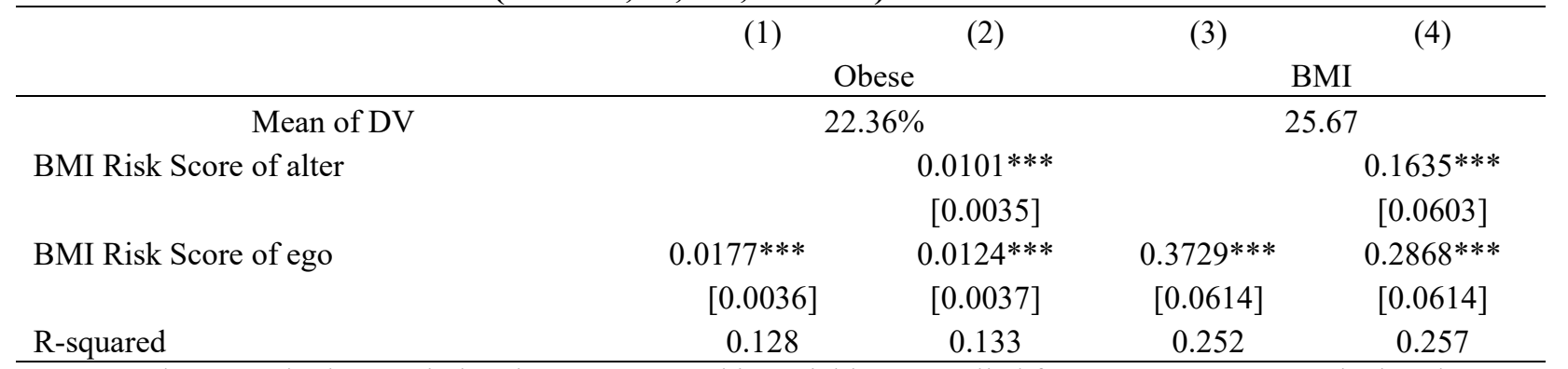

Notes: Robust standard errors in brackets. Demographic variables controlled for are age, sex, race, whether the respondent lives with parents, whether the siblings live together, total household income, the respondent's highest grade completed, marital status, employment status, and parental educational attainment. The reported number for Obese outcome is OLS coefficient. $* * * p<0.01, * * p<0.05, * p<0.1$

B. Wave I

\begin{tabular}{|c|c|c|c|c|}
\hline & (1) & (2) & (3) & (4) \\
\hline & \multicolumn{2}{|c|}{ Obese } & \multicolumn{2}{|r|}{ BMI } \\
\hline Mean of DV & & & & 22.7 \\
\hline BMI Risk Score of alter & & $\begin{array}{c}0.0106^{* * * *} \\
{[0.0039]}\end{array}$ & & $\begin{array}{c}0.1860^{* * *} \\
{[0.0548]}\end{array}$ \\
\hline BMI Risk Score of ego & $\begin{array}{r}0.0147 * * * \\
{[0.0040]}\end{array}$ & $\begin{array}{l}0.0093 * * \\
{[0.0041]}\end{array}$ & $\begin{array}{c}0.3085^{* * *} \\
{[0.0538]}\end{array}$ & $\begin{array}{c}0.2134 * * * \\
{[0.0520]}\end{array}$ \\
\hline R-squared & 0.074 & 0.083 & 0.120 & 0.132 \\
\hline
\end{tabular}

